\title{
ANTIOXIDANT EVALUATION AND PHYTOCHEMICAL CONTENT OF VARIOUS RICE BRAN EXTRACTS OF THREE VARIETIES RICE FROM SEMARANG, CENTRAL JAVA, INDONESIA
}

\author{
SUKRASNO, SLAMET TUTY, IRDA FIDRIANNY* \\ Department of , School of Pharmacy, Pharmaceutical Biology Research Group, Bandung Institute of Technology, Indonesia. \\ Email: irdafidrianny@gmail.com
}

Received: 12 December 2016, Revised and Accepted: 23 December 2016

\begin{abstract}
Objectives: The objectives of this research were to evaluate antioxidant activity from different polarities rice bran extract of three varieties of rice using two methods of antioxidant testing which were ferric reducing antioxidant power (FRAP) and 2,2-diphenyl-1-picrylhydrazyl (DPPH), and correlation of total phenolic, flavonoid and carotenoid content with their exhibitory concentration $50\left(\mathrm{EC}_{50}\right)$ of FRAP and inhibitory concentration 50 $\left(\mathrm{IC}_{50}\right)$ of DPPH antioxidant activities.
\end{abstract}

Methods: Extraction was conducted by reflux using different polarity solvents. The extracts were evaporated using rotary evaporator. Determination of total phenolic, flavonoid and carotenoid content, antioxidant activities using FRAP and DPPH assays was performed by ultraviolet-visible spectrophotometry and its correlation with $\mathrm{EC}_{50}$ of FRAP capacities and $\mathrm{IC}_{50}$ of DPPH scavenging activities was analyzed by Pearson's method.

Results: Ethanolic rice bran extract of black rice showed the lowest $\mathrm{EC}_{50}$ of FRAP capacity $64.35 \mu \mathrm{g} / \mathrm{ml}^{\mathrm{and}} \mathrm{IC} \mathrm{C}_{50}$ of $\mathrm{DPPH}$ scavenging activity $23.92 \mu \mathrm{g} / \mathrm{ml}$. The highest phenolic content, flavonoid content, and carotenoid content were also given by ethanolic rice bran extract of black rice. There was significantly negative correlation between total phenolic content and carotenoid content in rice bran extract of red rice and black rice with their $\mathrm{IC}_{50}$ of DPPH.

Conclusions: All of the rice bran extracts (except n-hexane rice bran extract of black rice and ethanolic rice bran extract of white rice) were very strong antioxidant by DPPH assay. Phenolic and carotenoid compounds in rice bran extracts of red rice and black rice were the major contributor in antioxidant activity by DPPH assay. Rice bran extracts of black rice had linear results by FRAP and DPPH assays.

Keywords: Antioxidant, 2,2-diphenyl-1-picrylhydrazyl, Ferric reducing antioxidant power, Rice bran, Three varieties, Rice.

(C) 2017 The Authors. Published by Innovare Academic Sciences Pvt Ltd. This is an open access article under the CC BY license (http://creativecommons. org/licenses/by/4. 0/) DOI: http://dx.doi.org/10.22159/ajpcr.2017.v10i6.16565

\section{INTRODUCTION}

Oxidative stress related with many diseases can be prevented by antioxidant. In normal condition, body can prevent oxidative stress, but in excessive oxidative stress condition body needs antioxidant to inhibit negative effect of oxidative stress. Previous researches revealed that antioxidant activities could be correlated to their phenolic and flavonoid content $[1,2]$. Phenolic compounds are commonly found in plants, and they have been expressed to give many pharmacological effects, included antibacterial and antioxidant activity [3,4]. Many plants contained phenolic and flavonoid compounds included rice, tea and citrus [2,5-7].

Antioxidant activity of vegetables, fruits, and food could determine using antioxidant testing methods such as ferric reducing antioxidant power (FRAP) 2,2'-azino-bis (3-ethylbenzthiazoline-6-sulfonic acid) (ABTS) and 2,2-diphenyl-1-picrylhydrazyl (DPPH) [5,6,8,9]. The previous studies figured that FRAP, DPPH, and ABTS methods could be used to evaluate antioxidant activity in many plants extracts $[9,10]$. The previous researches [11-14] exposed that rice and rice bran had antioxidant activities by using DPPH, FRAP, and ABTS assays.

The goals of this research were to determine antioxidant activities of different polarity rice bran extracts (n-hexane, ethyl acetate, and ethanol) of three varieties of rice grown in Semarang-Central Java, Indonesia, using DPPH and FRAP assays, and correlation of total phenolic, flavonoid and carotenoid content with their antioxidant activities.

\section{METHODS}

Materials

DPPH, FRAP, 2,4,6-tripyridyltriazine (TPTZ), gallic acid, quercetin, betacarotene were purchased from Sigma-Aldrich (MO, USA), rice bran of three varieties of rice. All of other reagents were analytical grades.

\section{Preparation of sample}

Rice bran of three varieties of rice (Oryza sp.) was rice bran of white rice namely as PUT, rice bran of red rice as MER, and rice bran of black rice as HIT were collected from Semarang-Central Java, Indonesia, were thoroughly washed with tap water, sorted while wet, cut, dried, and grinded into powder.

\section{Extraction}

About 300 g of powdered sample was extracted by reflux using different polarity solvents. Extraction using n-hexane was repeated three times. The remaining residue was then extracted three times by using ethyl acetate. Finally, the remaining residue was extracted three times using ethanol. Therefore totally, there were three n-hexane extracts (namely PUT1, MER1, and HIT1), three ethyl acetate extracts (PUT2, MER2, and HIT2), and three ethanol extracts (PUT3, MER3, and HIT3).

\section{Total phenolic content (TPC)}

Folin-ciocalteu reagent was used for determining TPC [15]. The absorbance was observed at wavelength $765 \mathrm{~nm}$ using ultraviolet-vis spectrophotometer Hewlett Packard 8435. Analysis was performed in triplicate for each extract. Gallic acid standard solution $(80-170 \mu \mathrm{g} / \mathrm{ml})$ 
was used to obtain a calibration curve. TPC was presented as percentage of total gallic acid equivalent per $100 \mathrm{~g}$ extract (g GAE/100 g).

\section{Total flavonoid content (TFC)}

TFC was conducted using method from Chang et al. [16]. The absorbance was measured at wavelength $415 \mathrm{~nm}$. Analysis was performed in triplicate for each extract. Quercetin standard solution $(20-140 \mu \mathrm{g} / \mathrm{ml})$ was used to obtain a calibration curve. The TFC was expressed as percentage of total quercetin equivalent per $100 \mathrm{~g}$ extract ( $\mathrm{g} \mathrm{QE} / 100 \mathrm{~g}$ ).

\section{Total carotenoid content (TCC)}

Modification of method from Thaipong et al. [9] was usedto evaluate TCC. Each extract was diluted in $\mathrm{n}$-hexane. The absorbance was measured at wavelength $470 \mathrm{~nm}$. Analysis was performed in triplicate for each extract. Beta carotene standard solution $(40-100 \mu \mathrm{g} / \mathrm{ml})$ was used to obtain a calibration curve. The TCC was represented as percentage of total beta-carotene equivalent per $100 \mathrm{~g}$ extract (g BE/100 g).

\section{FRAP capacity}

Method of Benzi with minor modificationwas used in preparing of FRA Psolution [17]. The FRAP solution was prepared in acetate buffer $\mathrm{pH}$ 3.6. Various concentration of each extract was added into FRAP solution $50 \mu \mathrm{g} / \mathrm{ml} \mathrm{(1:1)} \mathrm{to} \mathrm{initiate} \mathrm{the} \mathrm{reaction.} \mathrm{After} 30$ minutes incubation, the absorbance was observed at wavelength $593 \mathrm{~nm}$. Acetate buffer was used as a blank, FRAP $50 \mu \mathrm{g} / \mathrm{ml}$ as control and ascorbic acid as standard. Analysis was performed in triplicate for each extract and standard. Antioxidant capacity of each extract was determined by calculating percentage of antioxidant capacity based on increasing in Fe (II)-TPTZ absorbance. Exhibitory concentration 50 $\left(\mathrm{EC}_{50}\right)$ is concentration which can increase $50 \%$ absorbance of Fe (II)TPTZ. $\mathrm{EC}_{50}$ of FRAP capacity of each extract can be calculated using its calibration curve.

\section{DPPH scavenging activity}

DPPH solution was adopted from Blois's method [18] with minor modification. Various concentration of each extract was added into DPPH solution $50 \mu \mathrm{g} / \mathrm{ml}$ (volume 1:1) to initiate the reaction. The absorbance was measured after 30 minutes incubation at wavelength $515 \mathrm{~nm}$. Methanol was used as a blank, DPPH $50 \mu \mathrm{g} / \mathrm{ml}$ as control, and ascorbic acid as standard. Analysis was performed in triplicate for each extract and standard. Antioxidant activity of each extract by DPPH method was evaluated using reduction of DPPH absorbance by calculating the percentage of antioxidant activity [19]. Inhibitory concentration 50 (IC I $_{50}$ is concentration which can inhibit 50\% absorbance of DPPH. IC ${ }_{50}$ of DPPH scavenging activity of each extract can be calculated using its calibration curve.

\section{Statistical analysis}

Each sample analysis was performed in triplicate. All of the presented results are means ( \pm standard deviation) of at least three independent experiments. Statistical analysis using ANOVA with a statistical significance level set at $\mathrm{p}<0.05$ and post-hoc Turkey procedure was performed with SPSS 16 for Windows. Correlation between the total phenolic, flavonoid, carotenoid content, and antioxidant activities and correlation between two antioxidant activity methods were performed using the Pearson's method.

\section{RESULTS}

\section{$\mathrm{EC}_{50}$ of FRAP capacity and $\mathrm{IC}_{50}$ of DPPH scavenging activity}

The $\mathrm{EC}_{50}$ of FRAP capacities and $\mathrm{IC}_{50}$ of DPPH scavenging activities in various extracts of rice bran using FRAP and DPPH assays were shown in Figs. 1 and 2.

\section{TPC, TFC, and TCC in rice bran extracts}

TPC among the various extracts were reported in term of Gallic acid equivalent using the standard curve equation $y=0.0044 \mathrm{x}+0.023$, $\mathrm{R}^{2}=0.9978$. The TPC in various extracts of rice bran showed different result varied from 2.33 to $12.24 \mathrm{~g} \mathrm{GAE} / 100 \mathrm{~g}$. Ethanolic rice bran extract of black rice (HIT3) denoted the highest phenolic content $(12.24 \mathrm{~g}$
GAE/100 g) and the lowest (2.33 g GAE/100 g) given by n-hexane rice bran extract of white rice (PUT1)

TFC among the various extracts were presented in term of quercetin equivalent using the standard curve equation $\mathrm{y}=0.0037 \mathrm{x}+0.1913$, $\mathrm{R}^{2}=0.9996$. The $\mathrm{TFC}$ in various extracts of rice bran gave different result in the range of $0.46-18.74 \mathrm{~g} \mathrm{QE} / 100 \mathrm{~g}$. The highest TFC (18.74 g $\mathrm{QE} / 100 \mathrm{~g}$ ) was shown by ethanolic rice bran extract of black rice (HIT3).

TCC among the various extracts were reported in term of beta-carotene equivalent using the standard curve equation $y=0.0097 \mathrm{x}-0.1185$, $\mathrm{R}^{2}=0.9988$. The TCC in various extracts of rice bran had resulted in the range of 0.27-5.80 g BE/100 g. The highest carotenoid content $(5.80 \mathrm{~g}$ $\mathrm{BE} / 100 \mathrm{~g}$ ) was also given by ethanolic rice bran extract of black rice (HIT3), while ethanolic rice bran extract of red rice (MER3) gave the lowest carotenoid $(0.27 \mathrm{~g} \mathrm{BE} / 100 \mathrm{~g}$ )

Correlations between $\mathrm{EC}_{50}$ of FRAP capacities, $\mathrm{IC}_{50}$ of DPPH scavenging activities and total phenolic, flavonoid, carotenoid content in various rice bran extracts

TPC in various rice bran extracts of black rice had negative and significant correlation with their $\mathrm{EC}_{50}$ of FRAP capacities and $\mathrm{IC}_{50}$ of DPPH scavenging activities $(r=-1.000, p<0.01)$, while TPC in rice bran extracts of red rice only gave significantly negative correlation with their $\mathrm{IC}_{50}$ of DPPH scavenging activities $(\mathrm{r}=-0.978, \mathrm{p}<0.01)$. TFC in white rice bran extracts had a negative and significant correlation with their $\mathrm{IC}_{50}$ of DPPH scavenging activities ( $\mathrm{r}=-0.690, \mathrm{p}<0.05)$, while TFC in black rice bran extracts showed a significant and negative correlation with their $\mathrm{EC}_{50}$ of FRAP capacity $(\mathrm{r}=-0.999, \mathrm{p}<0.01)$. TCC in rice bran extracts of black rice was significantly negative correlation with their $\mathrm{IC}_{50}$ of DPPH scavenging activities and $\mathrm{EC}_{50}$ of FRAP capacities $(\mathrm{r}=-0.857 ; \mathrm{r}=-0.867$, $\mathrm{p}<0.01$, respectively) (Table 1 ).

\section{DISCUSSION}

The previous studies [12,20] reported that rice bran had antioxidant capacity. There was no study regarding antioxidant activity of various rice bran extracts (which were n-hexane, ethyl acetate, and ethanol) of three varieties rice from Semarang-Central Java, Indonesia, using DPPH and FRAP assays.

The $\mathrm{EC}_{50}$ of FRAP capacities and $\mathrm{IC}_{50}$ of DPPH scavenging activities in various rice bran extracts from three varieties rice using FRAP and DPPH assays were given in Figs. 1 and 2. The $\mathrm{EC}_{50}$ of FRAP capacities and $\mathrm{IC}_{50}$ of DPPH scavenging activities in various rice bran extracts compared to $\mathrm{EC}_{50}$ or $\mathrm{IC}_{50}$ of ascorbic acid standard. The lowest $\mathrm{EC}_{50}$ or $\mathrm{IC}_{50}$ means showed the highest antioxidant activity. Sample which had $\mathrm{IC}_{50}$ or $\mathrm{EC}_{50}$ lower than $50 \mu \mathrm{g} / \mathrm{ml}$ was a very strong antioxidant, $50-100 \mu \mathrm{g} / \mathrm{ml}$ was a strong antioxidant, $101-150 \mu \mathrm{g} / \mathrm{ml}$ was a medium

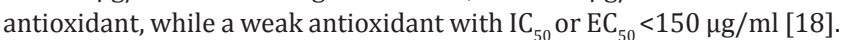

In the present research exposed that $\mathrm{EC}_{50}$ of FRAP capacities and $\mathrm{IC}_{50}$ of DPPH scavenging activities of various rice bran extracts from three varieties rice in the range of 64.35 to $387.90 \mu \mathrm{g} / \mathrm{ml}$ and 23.92-143.59 $\mu \mathrm{g} / \mathrm{ml}$, respectively. All of the rice bran extracts (except n-hexane black rice bran extract and ethanolic white rice bran extract) were categorized as very strong antioxidant using DPPH method, and only ethanolic rice bran extracts of white rice, red and black rice can be classified as strong antioxidant using FRAP method. The previous study [21] stated that phytic acid extract from rice bran denoted higher antioxidant activity by DPPH and beta-carotene linoleate bleaching assays (41.5\% and $93.36 \%)$ than phytic acid extract from corn $(26.4 \%$ and $92.55 \%$ ). In contrary with FRAP assay, phytic acid extract from corn showed higher antioxidant activity (2.78 $\mathrm{mM} \mathrm{FeSO}_{4}$ ) than phytic acid extract from rice bran (2.10 $\mathrm{mM} \mathrm{FeSO}_{4}$ ). Muntana and Prasong [20] studied regarding the antioxidant activity of rice bran extracts from 15 cultivars rice from Thailand, which was five cultivars white rice, five cultivars red rice and five cultivars glutinous black rice. The results of Muntana's research presented that the rice bran extract of red rice cultivar 5718 gave the highest antioxidant activity which had the 


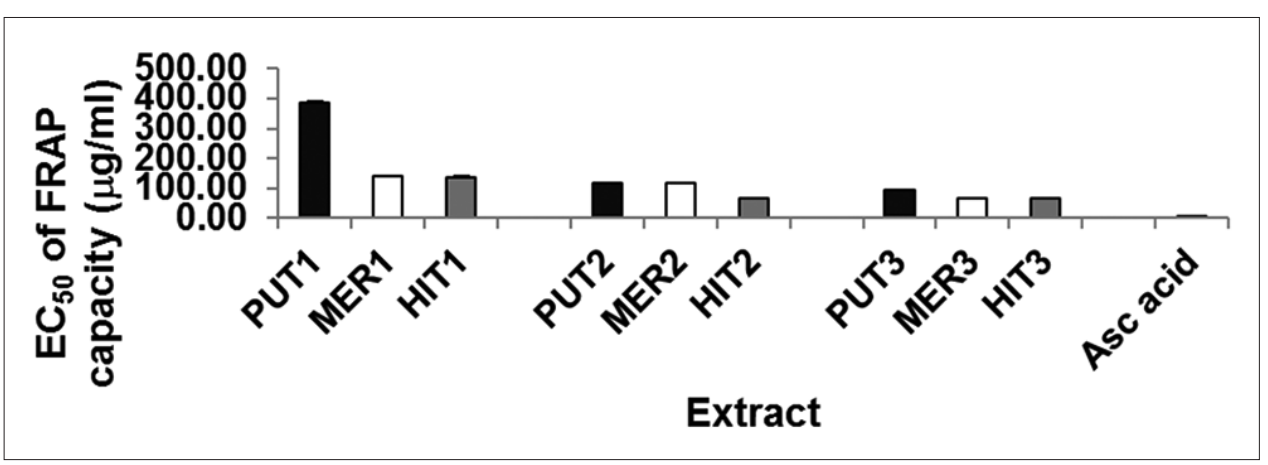

Fig. 1: $\mathrm{EC}_{50}$ of ferric reducing antioxidant power capacities in various rice bran extracts

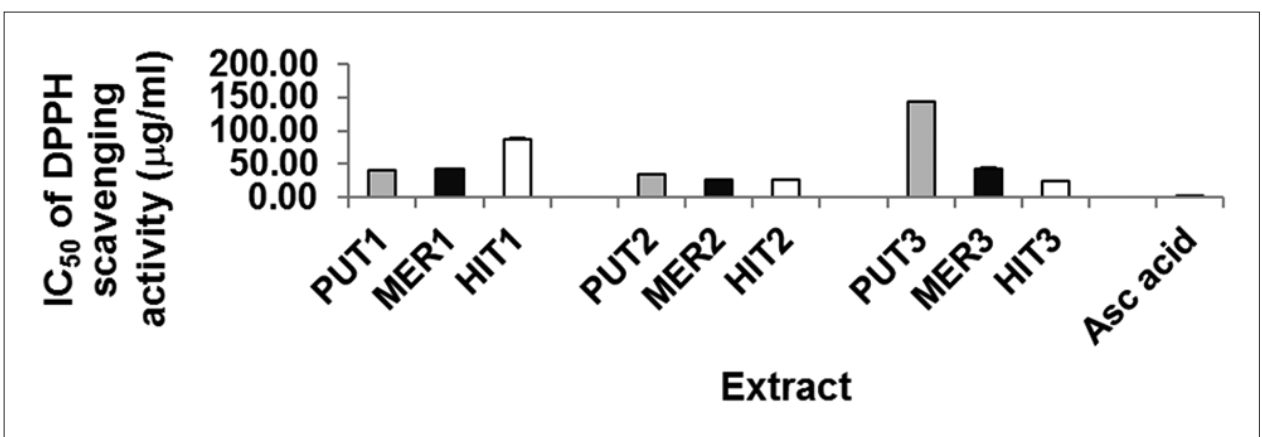

Fig. 2: Inhibitory concentration 50 of 2,2-diphenyl-1-picrylhydrazyl scavenging activities in various rice bran extracts

Table 1: Pearson's correlation coefficient of $\mathrm{EC}_{50}$ of FRAP capacities and $\mathrm{IC}_{50}$ of DPPH scavenging activities with their total phenolic, flavonoid, carotenoid content in various rice bran extracts

\begin{tabular}{|c|c|c|c|c|c|c|}
\hline \multirow[t]{2}{*}{ Parameter antioxidant } & \multicolumn{6}{|c|}{ Coefficient correlation Pearson (r) } \\
\hline & TPC & TFC & TCC & $\mathrm{EC}_{50}$ FRAP PUT & $\mathrm{EC}_{50}$ FRAP MER & EC $_{50}$ FRAP HIT \\
\hline $\mathrm{EC}_{50}$ FRAP PUT & $-0.487^{\mathrm{ns}}$ & $-0.268^{\mathrm{ns}}$ & $-0.356^{\mathrm{ns}}$ & & & \\
\hline $\mathrm{EC}_{50}^{50}$ FRAP MER & $0.411^{\mathrm{ns}}$ & $0.023^{\mathrm{ns}}$ & $0.394^{\mathrm{ns}}$ & & & \\
\hline $\mathrm{EC}_{50}^{50}$ FRAP HIT & $-1.000^{* *}$ & $-0.999 * *$ & $-0.867^{* *}$ & & & \\
\hline $\mathrm{IC}_{50}^{50}$ DPPH PUT & $-0.501^{\mathrm{ns}}$ & $-0.690^{*}$ & $0.620^{*}$ & $0.512^{\mathrm{ns}}$ & & \\
\hline $\mathrm{IC}_{50}^{50}$ DPPH MER & $-0.978 * *$ & $0.972 * *$ & $-0.982^{* *}$ & & $0.212^{\mathrm{ns}}$ & \\
\hline $\mathrm{IC}_{50} \mathrm{DPPH}$ HIT & $-1.000 * *$ & $0.999 * *$ & $-0.857^{* *}$ & & & $1.000^{* *}$ \\
\hline
\end{tabular}

PUT: White rice, MER: Red rice, HIT: Black rice, TPC: Total phenolic content, TFC: Total flavonoid content, TCC: Total carotenoid content, IC ${ }_{50}$ DPPH: IC $_{50}$ of DPPH

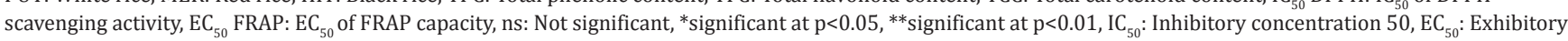
concentration 50, DPPH: 2,2-diphenyl-1-picrylhydrazyl, FRAP: ferric reducing antioxidant power

lowest $\mathrm{EC}_{50}$ of DPPH scavenging activity $(5.7 \mu \mathrm{g} / \mathrm{ml})$, followed by red rice cultivar $22699(8.4 \mu \mathrm{g} / \mathrm{ml})$. It was contrary with this study which exhibited that $\mathrm{IC}_{50}$ of DPPH of ethanolic rice bran extract of red rice and black rice were $43.43 \mu \mathrm{g} / \mathrm{ml}$ and $23.92 \mu \mathrm{g} / \mathrm{ml}$. While antioxidant activity using thiocyanate method demonstrated that antioxidant activity of red rice cultivar 22699 higher than cultivar 5718 of red rice [20]. The previous study [14] reported that $\mathrm{IC}_{50}$ of DPPH scavenging activities of $\mathrm{HCl}$ in ethanol extracts of six cultivars of red rice and six cultivars of black rice in the range of $100-1120 \mu \mathrm{g} / \mathrm{ml}$ and $140-590$ $\mu \mathrm{g} / \mathrm{ml}$, respectively. Chakuton et al. [13] represented that IC ${ }_{50}$ of DPPH scavenging capacity of methanolic extract of eight cultivars of colored rice varied from 535 to $49,746 \mu \mathrm{g} / \mathrm{ml}$, which was categorized as weak antioxidant. Li et al. [12] extracted crude polysaccharide (CPS) from fermented rice bran using $80 \%$ methanol. The results demonstrated that CPS extract $5 \mathrm{mg} / \mathrm{ml}$ gave the same percentage of DPPH scavenging activity $(96.16 \%)$ with ascorbic acid $5 \mathrm{mg} / \mathrm{ml}$. 80\% methanol CPS extract from rice bran had $\mathrm{EC}_{50}$ of DPPH $0.74 \mathrm{mg} / \mathrm{ml}$, while its $\mathrm{EC}_{50}$ of ABTS was $0.76 \mathrm{mg} / \mathrm{ml}$. Study by Zubair et al. [11] exposed that $80 \%$ methanolic extract of Basmati Pak rice variety showed the lowest $\mathrm{IC}_{50}$ of DPPH scavenging activity $(2,340 \mu \mathrm{g} / \mathrm{ml})$ compared to its $100 \%$ methanol extract and the other varieties, while its $100 \%$ ethanolic extract and $80 \%$ ethanolic extract had $\mathrm{IC}_{50}$ of DPPH 5,130 and
$5,150 \mu \mathrm{g} / \mathrm{ml}$, respectively. Research by Arab et al. [22] which extracted rice bran using methanol, ethanol and ethyl acetate by maceration method reported that percentage of radical scavenging activity of methanolic extract of Fajr rice bran was higher than its ethanolic extract and ethyl acetate extract, and percentage of DPPH scavenging activity of Fajr rice bran was higher than Tarem rice bran. Methanolic extract of Fajr rice bran $50 \mathrm{mg} / \mathrm{ml}$ showed the percentage of DPPH scavenging activity $93.91 \%$. It was similar to their antioxidant activity using reducing power assay which exposed that methanolic extract of Fajr rice bran gave higher antioxidant activity than the methanolic extract of Tarem rice bran. Methanolic extract of Fajr rice bran $50 \mathrm{mg} / \mathrm{ml}$ after incubation $96 \mathrm{~h}$ also showed higher antioxidant activity than its Tarem rice bran using linoleic acid system assay. The previous research [23] regarding antioxidant activity of rice bran extract from five varieties of rice in Pakistan, denoted that $80 \%$ methanolic extract of rice bran Super kernel (RB-kr) showed the highest antioxidant activity by DPPH, ABTS and linoleic acid system assays, compared to the other varieties (Super-2000, Super-basmati, Super-386, and Super-fine), which was similar to its $\gamma$-oryzanol content and tocopherol content. Rice bran super kernel (RB-kr) had the highest $\gamma$-oryzanol content (802 $\mu \mathrm{g} /$ $\mathrm{ml}$ ) and tocopherol content $(512 \mu \mathrm{g} / \mathrm{ml})$. Moko et al. [6] stated that $\mathrm{n}$-hexane fraction, ethyl acetate fraction and n-butanol fraction of red 
rice represented the percentage of DPPH scavenging capacities were 82.83 , 82.96 and $88.29 \%$, respectively, and the highest was given by n-butanol fraction of red rice. It was different from the present study which gave DPPH scavenging activities of n-hexane, ethyl acetate and ethanolic rice bran extracts of red rice were 43.56, 25.67 and 43.43 $\mu \mathrm{g} / \mathrm{ml}$, respectively, and the highest was taken by ethyl acetate rice bran extract of red rice. Rice contained many anthocyanin compounds which were cyanidin-3-glucoside and peonidin-3-glucoside [24]. These anthocyanins dissolve in ethyl acetate, ethanol, methanol and n-butanol solvents. Therefore, it can be predicted that n-butanol fraction of red rice contained many anthocyanins, which can act as antioxidant and gave higher antioxidant activity than their n-hexane and ethyl acetate fractions.

TPC might be contributed in antioxidant activity [25]. Flavonoid compounds in rice such as catechin, kaempferol, myricetin, and quercetin were included phenolic compounds [26]. The study by Iqbal et al. [23] denoted that TPC in $80 \%$ methanolic of different rice bran varieties gave TPC ranged from 0.251 to $0.359 \mathrm{~g} \mathrm{GAE} / 100 \mathrm{~g}$, and the highest was shown by rice bran-superkernel (RB-kr). It was contrary with the present study which exhibited that TPC in rice bran from white, red and black rice were 2.66, 2.42 and $12.40 \mathrm{~g} \mathrm{GAE} / 100 \mathrm{~g}$. Previous research [22] stated that methanolic extract of Fajr rice bran showed the highest TPC $(0.331 \mathrm{~g} \mathrm{GAE} / 100 \mathrm{~g})$ compared to Tarem rice bran and the other extracts. It was related with its antioxidant activity which gave the highest antioxidant activity by DPPH, reducing power and linoleic acid system assays. Methanol extracts of rice bran from fifteen cultivars rice in Thailand gave different results in TPC. Rice bran of red rice cultivar 5718 showed the highest TPC compared to the others. $80 \%$ methanolic extract of fermented rice bran exhibited higher TPC (89.83 mg GAE/g) than imfermented rice bran $(14.16 \mathrm{mg}$ GAE/100 g) [12]. The other studies [11] revealed that TPC in $80 \%$ methanolic rice extract of Basmati Pak variety presented the highest TPC $(0.275 \mathrm{~g}$ GAE $/ \mathrm{kg})$ compared to the other varieties and its $80 \%$ and $100 \%$ ethanolic extract. TPC in methanolic rice extract of cultivar 53 (7.40 mg GAE/100 g) was the highest among eight colored rice from Thailand [13]. Research by Sompong et al. [27] exposed that $85 \%$ aqueous methanol extract black rice showed TPC in the range of 336-665 mg ferulic acid equivalent (FAE)/100 g, and the red rice 79-691 mg FAE/100 g.

This study reported that TFC ethyl acetate rice bran extracts of three varieties of rice (white, red and black rice) 12.54, 0.46, and $18.73 \mathrm{~g}$ $\mathrm{QE} / 100 \mathrm{~g}$, respectively, and TFC in ethanolic rice bran extracts were $2.87,3.58$, and $18.74 \mathrm{~g} \mathrm{QE} / 100 \mathrm{~g}$. Rice contained many anthocyanin compounds [24] which were cyanidin-3-glucoside and peonidin-3glucoside. These anthocyanins dissolved in ethyl acetate, ethanol, methanol and n-butanol solvents. Therefore, some previous researches needed to determine total anthocyanin content (TAC) in rice extract. TAC in $85 \%$ aqueous methanol extract of 10 varieties of red rice ranged from 0.33 to $1.39 \mathrm{mg}$ cyanidin-3-glucoside equivalent (C3GE)/100 g [27], methanolic rice extract of cultivar 53 gave the highest TAC $(1045 \mathrm{mg}$ malvidin/100 g) among eight colored rice [13], TAC in n-hexane fraction, ethyl acetate fraction and n-butanol fraction of red rice were 4.58, 68.61, 42.25 mg C3GE/g, respectively [6]. Rice contained carotenoid compound such as beta-carotene, lutein and zeaxanthin [28], which act as antioxidant, soluble in n-hexane and ethyl acetate solvent. In the present study, it can be seen that TCC in n-hexane and ethanolic rice bran extracts of black rice (1.83 g BE/100 g and $5.80 \mathrm{~g} \mathrm{BE} / 100 \mathrm{~g}$ ) higher than TCC in rice bran extract of the white rice and red rice, while in ethyl acetate rice bran extract TCC in red rice (4.89 g BE/100 g) higher than the white rice and black rice.

Pearson's correlation coefficient was negatively significant if $-0.61 \leq r \leq-0.97$ and positively high if $0.61 \leq r \leq 0.97$ [9]. Sample which had the lowest $\mathrm{EC}_{50}$ of FRAP capacity and $\mathrm{IC}_{50}$ of DPPH scavenging activity had the highest antioxidant activity. Increasing in TPC, TFC and TCC caused increasing in antioxidant activities, which was stated by lower $\mathrm{EC}_{50}$ of FRAP capacity and or $\mathrm{IC}_{50}$ of DPPH scavenging activity.
Therefore, the good correlation between TPC, TFC and or TCC with their $\mathrm{EC}_{50}$ of FRAP or $\mathrm{IC}_{50}$ of DPPH is significantly negative correlation [29].

Data in Table 1 expressed that TPC, TFC, and TCC in rice bran extracts of black rice red rice had negative and significant correlation with their $\mathrm{EC}_{50}$ of FRAP capacities $(\mathrm{r}=-1.000 ; \mathrm{r}=-0.999 ; \mathrm{r}=-0.867$, $\mathrm{p}<0.01$, respectively). It can be predicted that phenolic, flavonoid and carotenoid compounds contributed together in antioxidant activities of rice bran extract of black rice by FRAP assay. There were significantly negative correlation between TPC and TCC in rice bran extracts of red rice $(\mathrm{r}=-0.978 ; \mathrm{r}=-0.982, \mathrm{p}<0.01)$ and black rice $(\mathrm{r}=-1.00 ; \mathrm{r}=-0.857$, $\mathrm{p}<0.01$ ). It can be supposed that phenolic and carotenoid compounds were the major contributor in antioxidant activities of rice bran extracts of red rice and black rice by DPPH assay. TFC in rice bran extracts of white rice had negative and significant correlation with their $\mathrm{IC}_{50}$ of DPPH scavenging activities $(r=-0.690, p<0.05)$. Based on the result, it can be concluded that flavonoid compounds were the major contributor in antioxidant activities of rice bran extracts of white rice using DPPH method.

Sample will act as antioxidant in FRAP assay if sample had reduction potential lower than $0.77 \mathrm{~V}$ which was reduction potential of Fe (III)/Fe (II); therefore, the sample had ability to reduce Fe (III) to Fe (II) and this sample will be oxidized and act as antioxidant [17]. Reagent of FRAP is $\mathrm{FeCl}_{3}$ that combined with TPTZ in acetate buffer pH 3.6. Complex of Fe (II) - TPTZ shows blue color and gave characteristic absorption at wavelength $593 \mathrm{~nm}$. Intensity of blue color depends on amount of Fe (III) which is reduced to Fe (II). The DPPH is stable free radicals which dissolve in methanol or ethanol and its colors show characteristic absorption at wavelength 515-520 nm. Colors of DPPH would be changed when the free radicals were scavenged by antioxidant [30].

Carotenoid has antioxidant capacity by scavenging free radical [31]. Beta carotene had conjugation double bonds; therefore, it had ability to scavenge free radicals and usually used as standard [32]. Study by Kobayashi and Sakamoto [33] revealed that the higher ability to scavenge free radical activity was given by increasing in lipophilicity of carotenoid. Beutner et al. [34] exposed that carotenoid which contains more than 7 double bonds will express the higher scavenging radical activity. In Fig. 5, it could be seen that TCC in n-hexane rice bran extract of black rice (HIT1) $1.83 \mathrm{~g} \mathrm{BE} / 100 \mathrm{~g}$ was higher than $\mathrm{n}$-hexane rice bran extract of red rice (MER1) $1.11 \mathrm{~g} \mathrm{BE} / 100 \mathrm{~g}$, however the $\mathrm{IC}_{50}$ of DPPH of MER1 (43.56 $\mu \mathrm{g} / \mathrm{ml}$ ) which was very strong antioxidant (Fig. 2), lower than IC $_{50}$ of DPPH of HIT1 $(87.88 \mu \mathrm{g} / \mathrm{ml})$ as strong antioxidant. It can be estimated that many carotenoid compounds in MER1 had more than 7 double bonds which had higher antioxidant activity and many carotenoid compounds in HIT1 contained maximum 7 double bonds.

Flavonoid had greater antioxidant activity than phenolic acid [35]. The flavonoid aglycones would give higher antioxidant activity than flavonoid glycosides. Flavonoid and phenolic acid were included in phenolic groups. Fig. 3 demonstrated that TPC in ethanolic rice bran extract of white rice (PUT3) $2.66 \mathrm{~g}$ GAE/100 g was similar to TPC in ethanolic rice bran extract of red rice (MER3) $2.42 \mathrm{~g} \mathrm{GAE} / 100 \mathrm{~g}$, but $\mathrm{IC}_{50}$ of DPPH scavenging activities of PUT3 $(143.59 \mu \mathrm{g} / \mathrm{ml})$ which was categorized as medium antioxidant, higher than $\mathrm{IC}_{50}$ of DPPH of MER3 (43.43 $\mu \mathrm{g} / \mathrm{ml}$ ) as very strong antioxidant. Based on the result, it might be supposed that MER3 contained many phenolic compounds which have high antioxidant activity, while PUT3 contained only a little phenolic compounds with high antioxidant activity. TPC in ethyl acetate rice bran extract of red rice (MER2) $8.45 \mathrm{~g} \mathrm{GAE} / 100 \mathrm{~g}$ was higher than TPC in ethanolic rice bran extract of red rice (MER3) $2.42 \mathrm{~g} \mathrm{GAE} / 100 \mathrm{~g}$, however MER3 showed higher antioxidant capacity by FRAP method (Fig. 1) which denoted by lower $\mathrm{EC}_{50}$ of FRAP $(66.35 \mu \mathrm{g} / \mathrm{ml})$ than $\mathrm{EC}_{50}$ of FRAP of MER2 $(118.24 \mu \mathrm{g} / \mathrm{ml})$. It could be seen that MER3 contained many phenolic compounds could reduce Fe(III)/Fe(II) and then Fe(II) react with TPTZ form blue color complex because their reduction potential lower than reduction potential of $\mathrm{Fe}(\mathrm{III}) / \mathrm{Fe}(\mathrm{II}) 0.77 \mathrm{~V}$, 


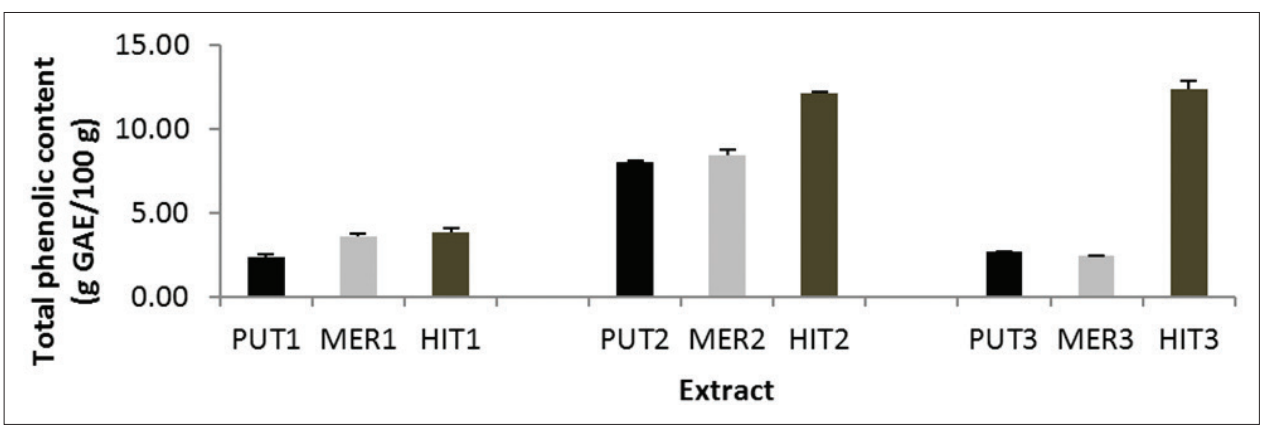

Fig. 3: Total phenolic content in various rice bran extracts

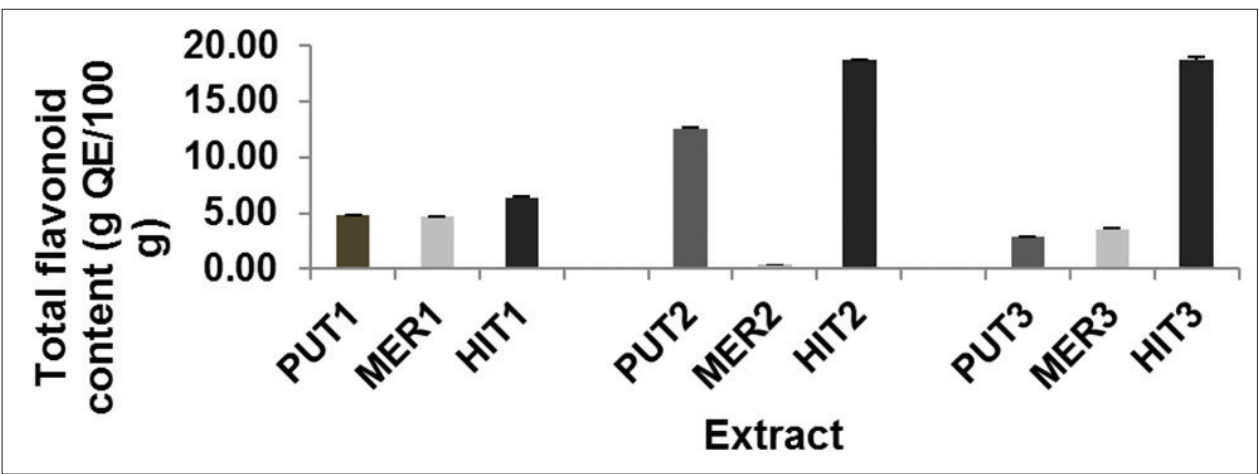

Fig. 4: Total flavonoid content in various rice bran extracts

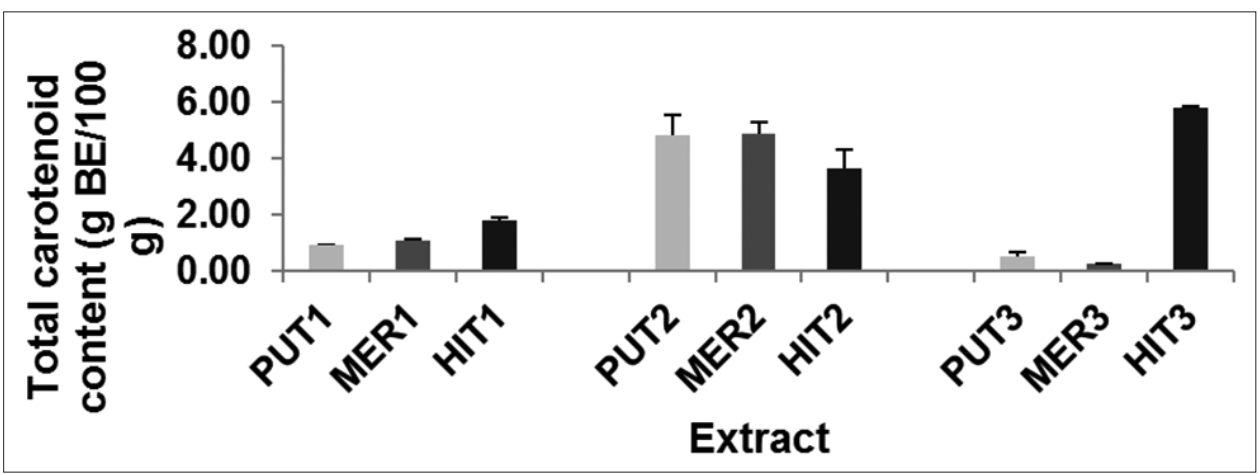

Fig. 5: Total carotenoid content in various rice bran extracts

meanwhile MER2 contained phenolic compounds with reduction potential higher than $0.77 \mathrm{~V}$.

Flavonoid will have high antioxidant activity which had ortho di $\mathrm{OH}$ at C-3'-C4', OH at C-3, oxo function at C-4, double bond at C-2 and C-3. The highest influence to antioxidant activity of flavonoid was given by ortho di $\mathrm{OH}$ at C-3'-C-4'. TFC in ethyl acetate rice bran extract of red rice (MER2) $0.46 \mathrm{~g} \mathrm{QE} / 100 \mathrm{~g}$ was lower than TFC in ethyl acetate rice bran extract of black rice (HIT2) $18.73 \mathrm{~g} \mathrm{QE} / 100 \mathrm{~g}$, but IC $\mathrm{I}_{50}$ of DPPH of MER2 $(25.67 \mu \mathrm{g} / \mathrm{ml})$ was similar to IC ${ }_{50}$ of DPPH of HIT2 $(26.30 \mu \mathrm{g} / \mathrm{ml})$. Based on the result, it can be predicted that almost all of flavonoid compounds in MER2 were flavonoid had ortho di-OH at C-3'-C-4' which gave higher antioxidant activity, meanwhile only a little flavonoid compounds in HIT2 had $\mathrm{OH}$ at position which can give high influence in antioxidant activity.

In general, FRAP and DPPH assays have the same mechanism reaction which is electron transfer. Electron transfer in DPPH assay, including ability to scavenge free radical of DPPH [36], meanwhile in FRAP assay depend on reduction potential of sample [17]. Data in Table 1 presented that Pearson's correlation coefficient of $\mathrm{EC}_{50}$ of FRAP capacity of rice bran extracts of black rice was significantly positive correlation with their $\mathrm{IC}_{50}$ of DPPH scavenging activities $(\mathrm{r}=1.000, \mathrm{p}<0.01)$. It could be concluded that DPPH and FRAP assays gave linear results in antioxidant activities of rice bran extracts of black rice.

\section{CONCLUSIONS}

Antioxidant activity of sample using various methods could give different results; therefore, it should be determined by different methods in parallel. All of the rice bran extracts (except $n$-hexane rice bran extract of black rice and ethanolic rice bran extract of white rice) were very strong antioxidant by DPPH assay. Phenolic and carotenoid compounds in rice bran extracts of red rice and black rice were the major contributor in antioxidant activities using DPPH method. DPPH and FRAP methods showed the linear result in antioxidant activities of rice bran extracts of black rice. Rice bran extracts of three varieties of rice may be exploited as natural antioxidant sources to reduce oxidative stress.

\section{REFERENCES}

1. Xu BJ, Chang SK. Total phenolic content and antioxidant properties of eclipse black beans (Phaseolus vulgaris L.) as affected by processing methods. J Food Sci 2008;73(2):H19-27. 
2. Ghasemi K, Ghasemi Y, Ebrahimzadeh MA. Antioxidant activity, phenol and flavonoid contents of 13 citrus species peels and tissues. Pak J Pharm Sci 2009;22(3):277-81.

3. Mokbel MS, Hashinaga F. Antibacterial and antioxidant activities of banana (Musa, AAA cv. Cavendish) fruits peel. Am J Biochem Biotechnol 2005;1(3):125-31.

4. Mashkor IM. Phenolic content and antioxidant activity of fenugreek seeds extract. Int J Pharmacogn Phytochem Res 2014;6(4):841-4.

5. Zielinski AA, Haminiuk CW, Alberti A, Nogueira A, Demiate IM, Granato DA. Comparative study of the phenolic compounds and the in vitro antioxidant activity of different Brazilian teas using multivariate statistical techniques. Food Res Int 2014;60:246-54.

6. Moko EM, Purnomo H, Kusnadi J, Ijong FG. Phytochemical content and antioxidant properties of colored and non colored varieties of rice bran from Minahasa, North Sulawesi, Indonesia. Int Food Res J 2104;21(3):1053-9.

7. Prakash NK, Bhuvaneswari S, Sripriya N, Prameela L, Bhagya R, Radhika B, et al. Antioxidant activity of common plants of northern Tamil Nadu, India. Int J Pharm Pharm Sci 2014;6(4):128-32.

8. Win M, Hamid A, Baharin B, Anwar FS, Pak-Dek MS. Phenolic compounds and antioxidant activity of peanut's skin, hull, raw kernel and roasted kernel flour. Pak J Bot 2011;43(3):1635-42.

9. Thaipong K, Boonprakob U, Crosby K, Zevallos LC, Byrne DH. Comparison of ABTS, DPPH, FRAP, and ORAC assays for estimating antioxidant activity from guava fruit extracts. J Food Comp Anal 2006;19:669-75.

10. Prasad MP, Rajkumar RA. In vitro antioxidant assay of citrus species using DPPH method. Indian J Adv Plant Res 2014;1(4):1-3.

11. Zubair M, Anwar F, Shahid SA. Effect of extraction solvents on phenolics and antioxidant activity of selected varieties of Pakistani rice (Oryza sativa L.). Int J Agric Biol 2012;14(6):935-40.

12. Li Y, Meng S, Shi M, Hu X, Yang Y, Zhang Z. Bioactivity evaluation of crude polysaccharide from rice bran fermented by Preussia aemulans and the changes in its nutritional contents. J Food Biochem 2016;40(5):664-72.

13. Chakuton K, Puangpronpitag D, Nakornriab M. Phytochemical content and antioxidant activity of colored and non-colored Thai rice cultivars. Asian J Plant Sci 2012;11(6):285-93.

14. Vichit W, Saewan N. Antioxidant activities and cytotoxicity of Thai pigmented rice. Int J Pharm Pharm Sci 2015;7(7):329-34.

15. Pourmorad F, Hosseinimehr SJ, Shahabimajd N. Antioxidant activity, phenol and flavonoid content of some selected Iranian medicinal plants. Afr J Biotechnol 2006;5(11):1142-5.

16. Chang CC, Yang MH, Wen HM, Chern JC. Estimation of total flavonoid content in propolis by two complementary colorimetric methods. J Food Drug Anal 2002;10:178-82.

17. Benzi IF, Strain JJ. The ferric reducing ability of plasma (FRAP) as a measure of antioxidant power: The FRAP assay. Anal Biochem 1996;239:70-6

18. Blois MS. Antioxidant determination by the use of stable free radicals.
Nature 1958;181:1199-2000.

19. Bedawey AA. Characteristics of Antioxidant Isolated from Some Plants Sources. Cairo: Shibin El-Kom; 2010. p. 1-11.

20. Muntana N, Prasong S. Study on total phenolic contents and their antioxidant activities of Thai white, red and black rice bran extracts. Pak J Biol Sci 2010;13(4):170-4.

21. Norhaizan ME, Ng SK, Norashareena MS, Abdah MA. Antioxidant and cytotoxicity effect of rice bran phytic acid as an anticancer agent on ovarian, breast and liver cancer cell lines. Mal J Nutr 2011;17(3):367-75.

22. Arab F, Alemzadeh I, Maghsoudi V. Determination of antioxidant component and activity of rice bran extract. Sci Iran 2011;18(6):1402-6.

23. Iqbal S, Bhanger MI, Anwar F. Antioxidant properties and components of some commercially available of rice bran in Pakistan. Food Chem 2005;93:265-72.

24. Yawadio R, Tanimori S, Morita N. Identification of phenolic compounds isolated from pigmented rices and their aldose reductase inhibitory activities. Food Chem 2007;101(4):1616-25.

25. Ling LT, Palanisamy UD. Review: Potential antioxidants from tropical plants. In: Valdez B, editor. Food Industrial Processes-Methods. Kuala Lumpur: In Tech; 1999. p. 64-72.

26. Du J, Yang T, Ceng YW, Pu XY, Yang SM, Chen XY, et al. Determination of flavonoid in rice grain by HPLC. J Plant Genet Resour 2013;13(5):896-900.

27. Sompong R, Ehn SS, Martin GL, Berghofer E. Physicochemical and antioxidative properties of red and black rice varieties from Thailand, China and Sri Lanka. Food Chem 2011;124:132-40.

28. Lamberts L, Delcour JA. Carotenoids in raw and parboiled brown and milled rice. J Agric Food Chem 2008;56(24):11914-9.

29. Fidrianny I, Johan Y, Sukrasno. Antioxidant activities of different polarity extracts from three organs of makrut lime (Citrus hystrix DC) and correlation with total flavonoid, phenolic, carotenoid content. Asian J Pharm Clin Res 2015;8(4):239-43.

30. Li XC, Wang XZ, Chen DF, Chen SZ. Antioxidant activity and mechanism of protochatechuic acid in vitro. J Funct Food Health Dis 2011;1:232-44.

31. Foote CS. Free Radicals in Biology. $3^{\text {rd }}$ ed. New York: Academic Press; 1976.

32. Charles DJ. Antioxidant Properties of Spices Shells and Other. London: John Willey; 2013

33. Kobayashi M, Sakamoto Y. Singlet oxygen quenching ability of astaxanthin esters from the green alga Haematococcus pluvialis. Biotech Lett 1999;21:265-9.

34. Beutner S, Bloedorn B, Hoffmann T, Martin HD. Synthetic singlet oxygen quenchers. Methods Enzymol 2000;319:226-41.

35. Heim KE, Tagliaferro AR, Bobilya DJ. Flavonoid antioxidants: Chemistry, metabolism and structure-activity relationships. J Nutr Biochem 2002; 13:572-84

36. Huang D, Ou B, Prior RL. The chemistry behind antioxidant capacity assays. J Agric Food Chem 2005;53:1841-56. 